Received 00th January 20xx, Accepted 00th January 20xx

DOI: $10.1039 / x 0 x \times 00000 x$

\section{Facile synthesis of novel lithium $\beta$-diketonate glyme adducts: the effect of molecular engineering on the thermal properties}

\author{
Nishant Peddagopu, ${ }^{\text {a }}$ Patrizia Rossi, ${ }^{\mathrm{b}}$ Carmela Bonaccorso, ${ }^{\mathrm{c}}$ Ausrine Bartasyte, ${ }^{\mathrm{d}}$ Paola Paoli, ${ }^{\mathrm{b}}$ and \\ Graziella Malandrino, ${ }^{a}$ *
}

Despite these promising advantages, industrial applications of a MOCVD process are still limited, likely because the commercial availability of starting molecular compounds is insufficient.

Very few lithium precursors are known for vapour phase processes, either MOCVD or atomic layer deposition. 19,20

Our previous studies have shown that glymes play a pivotal role in stabilizing complexes with the desired thermal properties for MOCVD applications. ${ }^{21,22}$ Glymes often behave like crown ethers in terms of coordinating/solvating ions of the alkaline-earth, $^{23,24}$ the transition $^{25,26}$ and the rare-earth metals ${ }^{22,27}$ through oxygen-ion complexation i.e. chelating properties, which leads to thermally stable and volatile adducts. Additionally, glymes have many other favourable properties including being liquid at a varied range of temperatures (typically $>200{ }^{\circ} \mathrm{C}$ ), low viscosity, high chemical and thermal stability, relatively low vapor pressure and low toxicity. ${ }^{28}$ Owing to these excellent solvent properties, glymes have been extensively used as solvents in liquid assisted MOCVD processes, either liquid injection or aerosol assisted. $^{29,30}$

Glymes have been also widely used to coordinate Li salts, proposed for lithium battery electrolyte applications, to produce crystalline solvate structures analysable through single crystal X-ray diffraction. ${ }^{31}$ Specifically, monoglyme (dimethoxyethane), diglyme (bis(2-methoxyethyl)ether), and triglyme (2,5,8,11-tetraoxa-dodecane) have been used to coordinate lithium in Li salts, yielding crystalline structures. Nevertheless, for some anions and glymes, liquid systems are observed. Henderson group has reported detailed studies on phase diagrams for glyme mixtures with simple lithium salts ${ }^{32}$ and crystallization kinetics of glymes with a wide range of lithium salts. ${ }^{33}$

As a merging point from all above mentioned considerations, we decided to synthesize novel lithium precursors using a $\beta$-diketone as anion and glyme as coordinating molecules. Here, we report on the synthesis of novel lithium complexes of the type "Li(hfa)•glyme", Hhfa= 1,1,1,5,5,5-hexafluoro-2,4-pentanedione, glyme= monoglyme, 
diglyme, triglyme and tetraglyme (2,5,8,11,14-pentaoxapentadecane). The mass transport properties, investigated through thermogravimetric analysis and differential scanning calorimetry, are highly affected by the glyme nature, which plays a key role in the thermal stability and volatility. They have been also characterized by FT-IR spectroscopy, ${ }^{1} \mathrm{H}$ and ${ }^{13} \mathrm{C}$ NMR. Single crystal $X$-ray diffraction studies provide evidence of interesting coordination moieties.

The complexes are synthesized in a single step reaction, from the lithium hydroxide monohydrate, $\mathrm{Hhfa}$ and glyme ligands in dichloromethane. A $\mathrm{LiOH} \bullet \mathrm{H}_{2} \mathrm{O}: \mathrm{Hhfa}$ :glyme stoichiometry of 1:1:1 was used for all the reactions, except for adduct 2 , when a 1:1:0.5 stoichiometry was used. The mixture was refluxed under stirring for 1 hour (Eq. (1)). Adducts $\mathbf{1}$ and $\mathbf{2}$ are solid while $\mathbf{3}$ and $\mathbf{4}$ are colorless liquids at room temperature.

$\mathrm{LiOH} \bullet \mathrm{H}_{2} \mathrm{O}+\mathrm{Hhfa}+$ glyme $\longrightarrow$ "Li(hfa)•glyme" $+\mathrm{H}_{2} \mathrm{O}$

1. $\left[\mathrm{Li}_{12}(\mathrm{hfa})_{12} \bullet \text { monoglyme } \bullet 4 \mathrm{H}_{2} \mathrm{O}\right]_{\mathrm{n}}$

2. $\left[\mathrm{Li}_{2}(\mathrm{hfa})_{2} \bullet\right.$ diglyme $\left.\bullet \mathrm{H}_{2} \mathrm{O}\right]$

3. $\mathrm{Li}(\mathrm{hfa}) \bullet$ triglyme $\bullet \mathrm{H}_{2} \mathrm{O}$

4. $\mathrm{Li}(\mathrm{hfa}) \bullet$ tetraglyme $\bullet \mathrm{H}_{2} \mathrm{O}$

Single crystal X-ray diffraction analysis were carried out for $\mathbf{1}$ and 2 (Table S1, ESI + ). The structure of the "Li(hfa)monoglyme" is very complex and the asymmetric unit is formed by $\left[\mathrm{Li}_{6}(\mathrm{hfa})_{6} \bullet 0.5\right.$ monoglyme] with two water molecules coordinated (Fig. 1), to give a structure of $\left[\mathrm{Li}_{12}(\mathrm{hfa})_{12} \bullet \text { monoglyme } \bullet 4 \mathrm{H}_{2} \mathrm{O}\right]_{\mathrm{n}}$. The structure involves polymeric chains (Fig. S1, Table S2), formed due to the coordination of hfa bridging two adjacent lithium ions, which are held together by monoglyme bridges. Thus, lithium ions are either four- or five coordinated due to the presence of a $\mathrm{H}_{2} \mathrm{O}$ molecule.

The diglyme adduct (Fig. 2) shows a dimeric unit $\left[\mathrm{Li}_{2}(\mathrm{hfa})_{2} \bullet\right.$ diglyme $\bullet \mathrm{H}_{2} \mathrm{O}$, where both lithium ions are fivecoordinated. The unit consists of a $\mathrm{Li}$ ion coordinated by two hfa molecules and one $\mathrm{H}_{2} \mathrm{O}$ molecule, while the coordination sphere of the second $\mathrm{Li}$ ion is completed by three oxygen of the diglyme and two oxygen atoms from the two hfa ligands, which bridge the lithium ions.

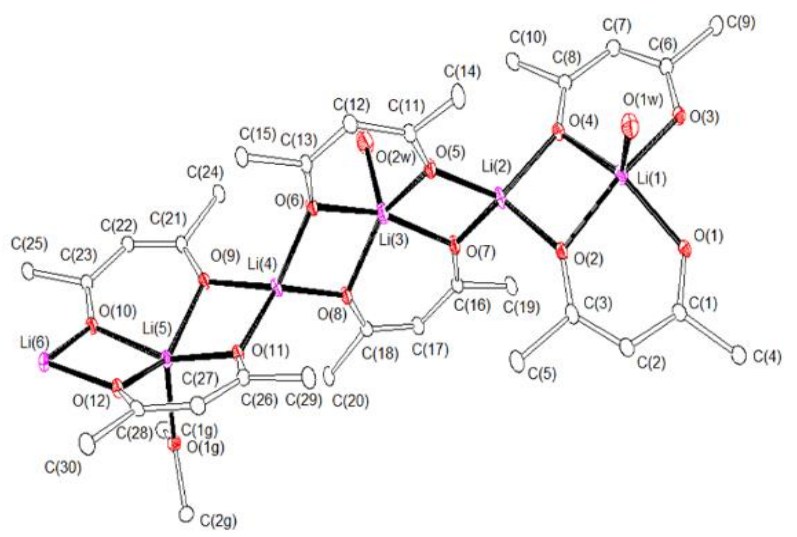

Fig. 1. Ortep view of the $\left[\mathrm{Li}_{6}(\mathrm{hfa})_{6} \bullet 0.5\right.$ monoglyme $\left.\bullet 2 \mathrm{H}_{2} \mathrm{O}\right]$ asymmetric unit (the monoglyme ligand possesses a centre of symmetry). Hydrogen atoms and fluorine atoms have been omitted for sake of clarity. Ellipsoids are at $20 \%$ probability.

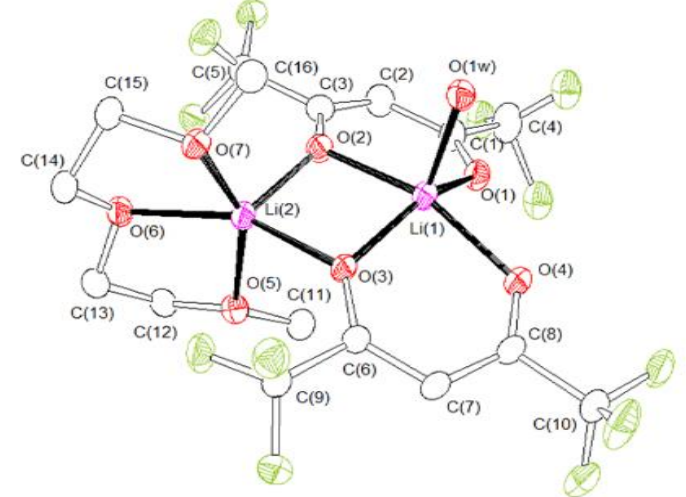

Fig. 2. Ortep view of the dinuclear complex $\left[\mathrm{Li}_{2}(\mathrm{hfa})_{2} \bullet\right.$ diglyme $\left.\bullet \mathrm{H}_{2} \mathrm{O}\right]$. Hydrogen atoms have been omitted for sake of clarity, just one model for the fluorin
atoms bonded to $C(5)$ has been reported. Ellipsoids are at $20 \%$ probability.

In the crystal lattice, centrosymmetric dimers are formed through two identical pairs of strong $\mathrm{H}$-bonds involving the water molecule working as $\mathrm{H}$-bond donor and the hfa oxygen atoms $\mathrm{O}(1)$ and $\mathrm{O}(4)$ that act as acceptors (Fig. S2, Table S3). The Fourier transform infrared (FT-IR) spectra, recorded in the range $4000-500 \mathrm{~cm}^{-1}$ (Fig. S3), have allowed to confirm the formation of the adducts, and specifically also of the liquid adducts $\mathbf{3}$ and $\mathbf{4}$.

In the spectra of the adducts $\mathbf{2 ,} \mathbf{3}$ and $\mathbf{4}$ we observe a broad band around $3600 \mathrm{~cm}^{-1}$ due to the $\mathrm{OH}$ stretching modes of coordinated water. Comparing the FT-IR spectra of all the four adducts and that of the $\mathrm{H}$-hfa ligand in the carbonyl range, it is possible to observe that the two peaks at about $1660 \mathrm{~cm}^{-1}$ and $1530 \mathrm{~cm}^{-1}$, associated respectively with the $\mathrm{C}=\mathrm{O}$ and $\mathrm{C}=\mathrm{C}$ stretchings, are indicative of the hfa ligand coordination. The shifting of these peaks observed also in the "Li(hfa)•glyme" 3 and 4 adducts (an enlarged region in the range $1800-1400 \mathrm{~cm}^{-1}$ is reported in Fig. S4) compared to those of the free ligand, suggests that the lithium ion is actually coordinated by the hfa ligand and the liquid compounds are not a mixture of ligands.

Further confirmation of the formation of the liquid adducts has been obtained through recording the ${ }^{1} \mathrm{H}-\mathrm{NMR}$ spectra. The binding of the metal cation affects the signals of the ${ }^{1} \mathrm{H} N M R$ spectra of the triglyme (Fig. 3) and tetraglyme (Fig. S5) ligands. Significant chemical shift changes are observed for almost all the protons of the triglyme ligand in the adduct 3: the methylene protons of the innermost portion undergo an upfield shift while the external methyl groups experience a downfield shift. These observations provide further evidence that the metal ion is coordinated through the oxygen atoms and that the ligands rearrange upon complexation. A similar trend is observed for the tetraglyme adduct 4 (Fig. S5). In addition the integrations of the ${ }^{1} \mathrm{H}-\mathrm{NMR}$ peaks of $\mathbf{3}$ (Fig. S10) and 4 (Fig. S12) confirm a 1:1 hfa:glyme ratio in adducts 3 and 4 , thus pointing to the formation of complexes with formula $\mathrm{Li}(\mathrm{hfa}) \bullet$ triglyme and Li(hfa)•tetraglyme.

The ${ }^{1} \mathrm{H}$ and ${ }^{13} \mathrm{C}$ NMR data of all the adducts and their interpretation are reported in the supporting information (Fig. S6-S13).

The above mentioned findings may be interestingly compared with the data reported by Watanabe group $^{34-36}$ for $\mathrm{Li}$ complexes prepared by mixing lithium bis(trifluoromethyl- 


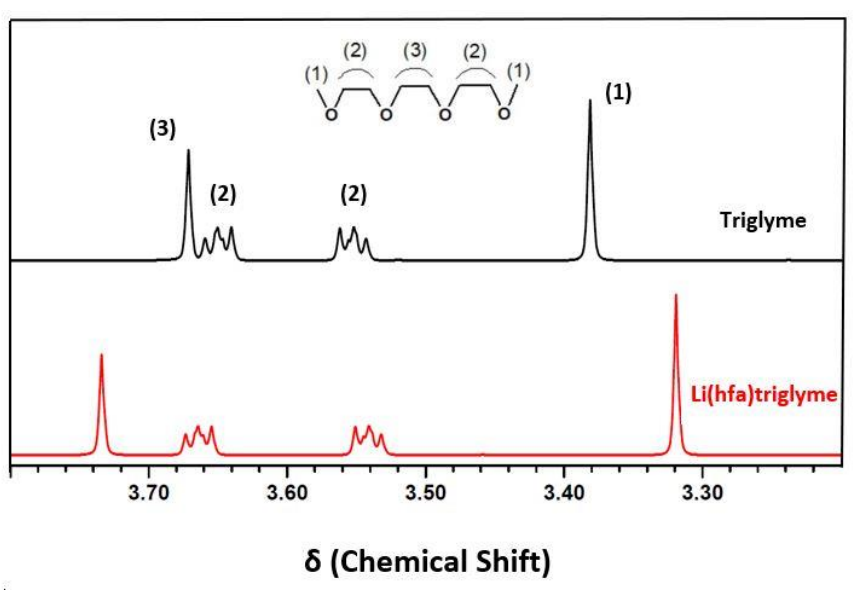

Fig. 3. Comparison of ${ }^{1} \mathrm{H}-\mathrm{NMR}$ spectra (polyether region) of Triglyme $(-)$ and Li(hfa)•triglyme $(-)$.

sulfonyl)-amide and triglyme or tetraglyme in a 1:1 molar ratio. Clear liquids were obtained also in those cases and their behaviour as room temperature ionic liquid was discussed as well. $^{34-36}$

For other anions $\left(\mathrm{X}=\mathrm{CF}_{3} \mathrm{SO}_{3}{ }^{-}, \mathrm{BF}_{4}{ }^{-}, \mathrm{ClO}_{4}{ }^{-}, \mathrm{AsF}_{6}{ }^{-}\right.$, and $\left.\mathrm{PF}_{6}{ }^{-}\right)$solid crystalline structures have been observed for the (triglyme) ${ }_{1}: \mathrm{LiX}$ with the $\mathrm{Li}$ ion in a four- to five- coordinated environment, ${ }^{37,38}$ while for $\mathrm{AsF}_{6}^{-}, \mathrm{BF}_{4}^{-}, \mathrm{CF}_{3} \mathrm{CO}_{2}^{-}$anions tetraglyme gives crystalline structures with a six-coordination sphere for $\mathrm{Li}^{+}$. 39

Similar four- or five-coordination moieties have been observed through ab-initio studies for Li-triglyme and Li-tetraglyme systems by Lindgren group. ${ }^{40,41}$ They suggested that the high chain flexibility of glymes enables many stable structures within a narrow energy range with very different geometrical arrangements of the ether oxygens. ${ }^{40,41}$

Coordination numbers ranging from four to six have been also found for $L i$ in alkoxides and $\beta$-diketonates complexes, see ref. 42 and references therein.

The thermal behaviours of the as-synthesized precursors have been investigated by thermogravimetric (TG) measurements (Fig. 4a) and differential scanning calorimetry (DSC) (Fig. 4b), which are thereby compared with the behaviour of the commercial precursor i.e. $\mathrm{Li}(\mathrm{tmhd})\left(\mathrm{H}_{2} \mathrm{O}\right)_{2},(2,2,6,6$-tetramethyl3,5-heptanedionato lithium dihydrate). TG curves of the "Li(hfa)•glyme" 1, 3 and $\mathbf{4}$ show a two steps mass loss associated with the $\mathrm{H}_{2} \mathrm{O}$ molecule loss around $100{ }^{\circ} \mathrm{C}$ and to vaporization of the adducts. Specifically, adduct $\mathbf{1}$ shows a weight loss of about $5.6 \%$ in the range $25-140^{\circ} \mathrm{C}$, which accounts for the loss of the four water molecules and the monoglyme of the $\left[\mathrm{Li}_{12}(\mathrm{hfa})_{12} \bullet \text { monoglyme } \bullet 4 \mathrm{H}_{2} \mathrm{O}\right]_{\mathrm{n}}$ polymeric structure, the theoretical weight loss being equal to $5.9 \%$. The main mass loss due to the adduct vaporization occurs in the range $230-340{ }^{\circ} \mathrm{C}$, with a residue of $6.2 \%$. The vaporization of $\mathrm{Li}(\mathrm{tmhd})\left(\mathrm{H}_{2} \mathrm{O}\right)_{2}$ occurs in two steps as well, the first one $(10.5 \%$ at $100{ }^{\circ} \mathrm{C}$ ) is associated with the loss of two water molecules and the second one is associated with the complex vaporization with a residue at $300{ }^{\circ} \mathrm{C}$ of $3.3 \%$.
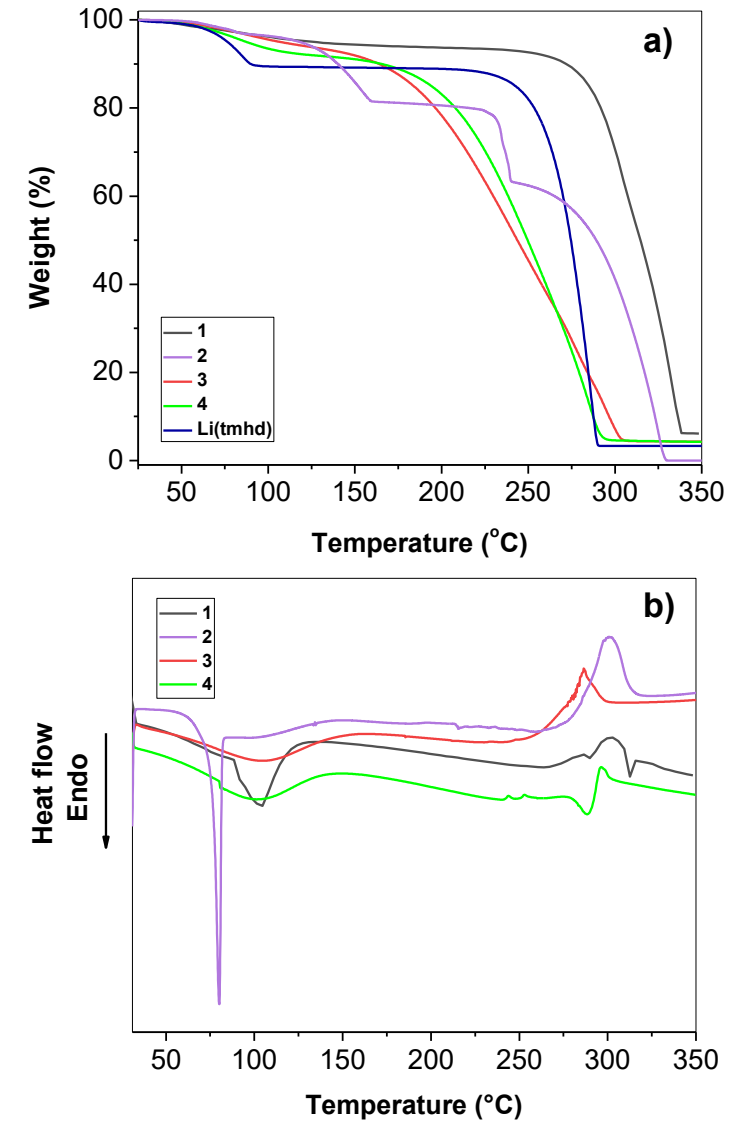

Fig. 4. TG curves (a) of the four "Li(hfa) •glyme" adducts vs. Li(tmhd). DSC curves (b) of the four "Li(hfa)・glyme" adducts.

Depending on the synthetic procedures water-free tetrameric units of $[\mathrm{Li}(\mathrm{tmhd})]_{4}\left([\mathrm{Li}(\mathrm{dpm})]_{4}\right.$ following the previous used nomenclature of dipivaloylmethane for the $\mathrm{Htmhd}$ ) have been found, showing an higher residue in the TG analysis. ${ }^{43,44}$ The range temperature of vaporization of $\mathbf{1}$ is higher than the commercial $\mathrm{Li}(\mathrm{tmhd})\left(\mathrm{H}_{2} \mathrm{O}\right)_{2}$ precursor, but this is not a drawback for its applications in liquid assisted MOCVD processes, given its solubility in common organic solvents.

The TG curves of adducts 3 and 4 (Fig. 4 a) show a $6.5 \%$ and 8.2 $\%$, respectively, weight loss in the range $25-130{ }^{\circ} \mathrm{C}$ due to water loss and a successive step weight loss with a residue of $4.3 \%$ at $300{ }^{\circ} \mathrm{C}$ and of $4.4 \%$ at $300{ }^{\circ} \mathrm{C}$, respectively. The TG curve of the $\left[\mathrm{Li}_{2}(\mathrm{hfa})_{2} \bullet\right.$ diglyme $\left.\bullet \mathrm{H}_{2} \mathrm{O}\right]$ adduct shows a threestep weight loss, indicating decomposition of the complex, with a residue of $1 \%$ at $330{ }^{\circ} \mathrm{C}$. Interpretation of the individual steps is not straightforward, but the IR spectra recorded in function of temperature (Fig. S14) allow to confirm that diglyme is partially lost after heating up to $160^{\circ} \mathrm{C}$ and it is completely lost at $250{ }^{\circ} \mathrm{C}$, since the peaks at $1004 \mathrm{~cm}^{-1}, 946$ $\mathrm{cm}^{-1}$ and $874 \mathrm{~cm}^{-1}$, due to the glyme coordination, ${ }^{45}$ are missing on heating the sample. It is worthy to note that the presence of $\mathrm{H}_{2} \mathrm{O}$ molecules in the coordination sphere of $\mathrm{Li}$ ion is not a drawback for the thermal properties of present complexes, and actually a good thermal behaviour for MOCVD applications has been previously observed for the $\mathrm{Mg}(\mathrm{hfa})_{2} \cdot 2 \mathrm{H}_{2} \mathrm{O} \cdot 2$ diglyme ${ }^{24}$ and $\mathrm{Co}(\mathrm{hfa})_{2} \cdot 2 \mathrm{H}_{2} \mathrm{O} \cdot$ tetraglyme $^{26}$ 


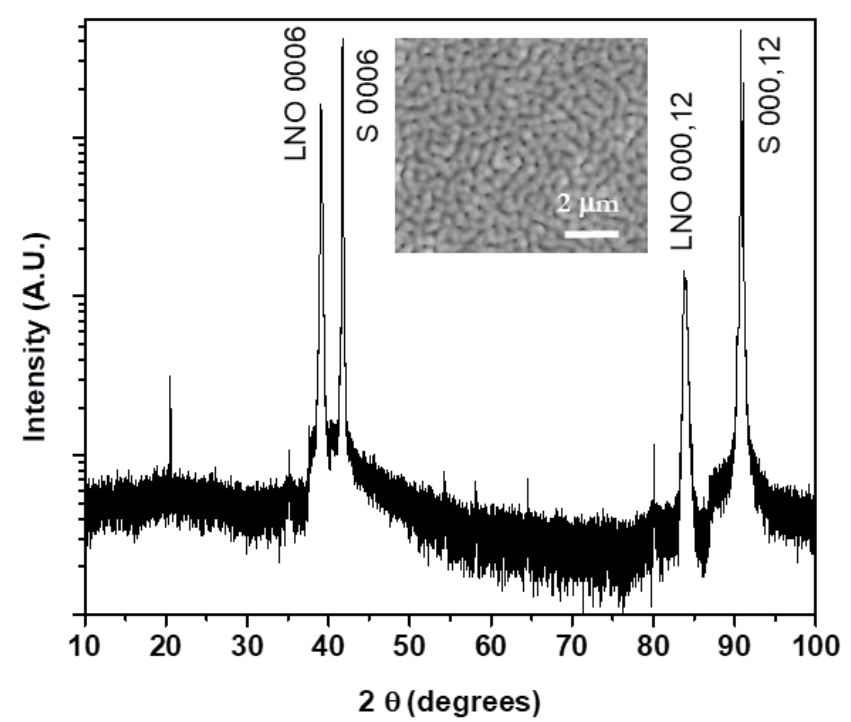

Fig. $5 \mathrm{X}$-ray diffraction pattern of a $\mathrm{LiNbO}_{3}$ (LNO) film deposited at $775^{\circ} \mathrm{C}$ on C-sapphire (S) using the monoglyme adduct 1 and the $\mathrm{Nb}(\text { tmhd })_{4}$. The inset reports the $\mathrm{SEM}$ image of the film.

adducts, despite the presence of $\mathrm{H}_{2} \mathrm{O}$ molecules in the coordination sphere.

The DSC curves of adduct 1 shows a broad endothermic peak around $100{ }^{\circ} \mathrm{C}$, likely associated with the loss of $\mathrm{H}_{2} \mathrm{O}$ molecules, and a small, sharp endothermic peak at $312.6{ }^{\circ} \mathrm{C}$, which may be associated with melting of the polymeric structure. The DSC curve of adduct $\mathbf{2}$ presents a sharp endothermic peak at $80.3^{\circ} \mathrm{C}$ due to the adduct melting and a broad exothermic peak at $300{ }^{\circ} \mathrm{C}$, which can be associated with its partial decomposition. In the case of the adducts $\mathbf{3}$ and $\mathbf{4}$, very broad peaks around $100{ }^{\circ} \mathrm{C}$ are observed and are due to the $\mathrm{H}_{2} \mathrm{O}$ molecule loss, while the exothermic peaks around 290 ${ }^{\circ} \mathrm{C}$ may be associated with vaporization overlapped with partial decomposition of the products.

Preliminary deposition experiments have been carried out in a pulsed liquid injection MOCVD reactor using the $\left[\mathrm{Li}_{12}(\mathrm{hfa})_{12} \bullet \text { monoglyme } \bullet 4 \mathrm{H}_{2} \mathrm{O}\right]_{\mathrm{n}}$ adduct and $\mathrm{Nb}(\text { tmhd })_{4}$ in a $2: 1$ ratio dissolved in monoglyme solvent. The films have been grown on C-sapphire substrate at a deposition temperature of $775^{\circ} \mathrm{C}$, other deposition details are reported in the ESIt. The XRD pattern (Fig. 5) shows peaks at $39.05^{\circ}$ and $83.78^{\circ}$ attributable to the 0006 and 000,12 reflections, respectively, of the $\mathrm{LiNbO}_{3}$ phase, while the peaks at $41.72^{\circ}$ and $91.03^{\circ}$ are associated with the 0006 and 000,12 reflections, respectively, of the $\mathrm{C}-\mathrm{Al}_{2} \mathrm{O}_{3}$ substrate. The unique presence of the $000 \mathrm{l}$ peaks indicates the formation of a highly c-axis oriented $\mathrm{LiNbO}_{3}$ film, while the scanning electron microscopy (SEM) image (inset in Fig. 5) points to the formation of a very homogeneous surface.

In conclusion, the reported research provides a detailed study on the syntheses of four novel adducts of lithium. The straightforward one-pot nature of the presently reported synthetic route envisages the possibility to easily synthesize and produce these precursors on large scale for industrial applications. TG data and the good solubility of the adduct $\mathbf{1}$ in common organic solvents, even though it is a polymeric structure, make this precursor suited for MOCVD applications. In addition, it is evident from the TG analyses that also the adducts $\mathbf{3}$ and $\mathbf{4}$ represent viable options in comparison to $\mathrm{Li}(\mathrm{tmhd})\left(\mathrm{H}_{2} \mathrm{O}\right)_{2}$, owing to their single step mass loss, low residue and comparable vaporization temperatures.

Thus, engineering of the $\mathrm{Li}^{+}$ion coordination sphere has yielded interesting adducts with functional properties that make them attractive for applications in MOCVD processes of $\mathrm{LiNbO}_{3}$, as assessed from the preliminary results reported in the present manuscript.

This work is supported by the European Community under the Horizon 2020 Programme in the form of the MSCA-ITN-2016 ENHANCE project, Grant Agreement N.722496.

\section{Conflicts of interest}

There are no conflicts to declare.

\section{Notes and references}

1 M. Schröder, A. Haußmann, A. Thiessen, E. Soergel and T. Woike, Adv. Funct. Mater., 2012, 22, 3936-3944.

2 D. Xue and K. Kitamura, Ferroelectrics, 2003, 297, 19-27.

3 Z. Chen, J. Huang, Y. Yang, Y. Wang, Y. Wu, H. He, X. Wei, Z. Ye, H. Zeng, H. Cong and Z. Jiang, RSC Adv., 2012, 2, 7380-7383.

4 R. Grange, J. W. Choi, C. L. Hsieh, Y. Pu, A. Magrez, R. Smajda, L. Forro and D. Psaltis, Appl. Phys. Lett., 2009, 95, 143105.

5 R. Bhatt, I. Bhaumik, S. Ganesamoorthy, R. Bright, M. Soharab, A. K. Karnal and P. K. Gupta, Crystals, 2017, 7, 23.

6 D. Kwei, C. Wang, H. Wang, X. Hu, D. Wei, X. Fang, Y. Zhang, D. Wu, Y. Hu, J. Li, S. Zhu and M. Xiao, Nat. Photonics, 2018, 12, 596-600.

7 W. Yang, P. G. Kazansky and Y. P. Svirko, Nat. Photonics, 2008, 2, 99104.

8 C. Wang, M. Zhang, X. Chen, M. Bertrand, A. Shams-Ansari, S Chandrasekhar, P. Winzer and M. Loncar, Nature, 2018, 562, 101104.

9 A. Guarino, G. Poberaj, D. Rezzonico, R. Degl'Innocenti and P. Günter, Nat. Photonics, 2007, 1, 407-410.

10 M. H. Dunn and M. Ebrahimzadeh, Science, 1999, 286, 1513-1517.

11 K. Buse, A. Adibi and D. Psaltis, Nature, 1998, 393, 665-668.

12 T. Fukuda and H. Hirano, J. Cryst. Growth, 1980, 50, 291-298.

13 J. Ye, X. Sun, Z. Wu, J. Liu and Y. An, J. Alloys Comp., 2018, 768, 750755.

14 M. A. Fakhri, E. T. Salim, A. W. Abdulwahhab, U. Hashim and Z. T. Salim, Optics \& Laser Technol., 2018, 103, 226-232.

15 a) A. Bartasyte, S. Margueron, T. Baron, S. Oliveri and P. Boulet, Adv. Mater. Interfaces, 2017, 4, 1600998; b) A Almirall, S. Oliveri, W. Daniau, S. Margueron, T. Baron, P. Boulet, S. Ballandras, S. Chamaly, A. Bartasyte, Appl. Phys. Lett., 2019, 114, 162905/1-162905/5.

16 A. Dabirian, Y. Kuzminykh, S. Cosmin Sandu, S. Harada, E. Wagner, P. Brodard, G. Benvenuti, S. Rushworth, P. Muralt, and P. Hoffmann, Cryst. Growth Des., 2011, 11, 203-209.

17 M. Iwai, M. Ohmori, T. Yoshino, S. Yamaguchi, and M. Imaeda, Jpn. J. Appl. Phys., 2004, 43, 8195-8198.

18 A. C. Jones and M. L. Hitchman, Chemical Vapour Deposition: Precursors, Processes, Applications, Royal Society of Chemistry, Cambridge UK, 2009.

19 J. A. Ocón, J. G. Murillo, M. Miki-Yoshida, M. N. Cardoza and O. E. Contreras-López, J. Cryst. Growth, 2014, 408, 64-70.

20 M. Nisula, Y. Shindo, H. Koga and M. Karppinen, Chem. Mater., 2015, 27, 6987-6993. 
21 G. G. Condorelli, G. Malandrino and I. L. Fragalà, Coord. Chem. Rev., 2007, 251, 1931-1950.

22 G. Malandrino and I. L. Fragala, Coord. Chem. Rev. 2006, 250, 16051620.

23 G. Malandrino, I. L. Fragala, D. A. Neumayer, C. L. Stern, B. J. Hinds and T. J. Marks, J. Mater. Chem., 1994, 4, 1061-1066.

24 M. E. Fragalà, R. G. Toro, P. Rossi, P. Dapporto and G. Malandrino, Chem. Mater., 2009, 21, 2062-2069.

25 H. Liu, S. Battiato, A. L. Pellegrino, P. Paoli, P. Rossi, C. Jiménez, G. Malandrino and D. Munoz-Rojas, Dalton Trans., 2017, 46,1098610995.

26 A. Gulino, P. Dapporto, P. Rossi, and I. Fragalà, Chem. Mater., 2003, 15, 3748-3752.

27 G. Malandrino, R. Lo Nigro, C. Benelli, F. Castelli and I. L. Fragalà, Chem. Vap. Deposition, 2000, 6, 233-238.

28 S. Tanga and H. Zhao, RSC Adv., 2014, 4, 11251-11287.

29 S. Battiato, J.L. Deschanvres, H. Roussel, L. Rapenne, B. Doisneau, G. G. Condorelli, D. Munoz-Rojas, C. Jiménez and G. Malandrino, Dalton Trans., 2016, 45, 17833-17842

30 S.-T. Zhang, M. Modreanu, H. Roussel, C. Jiménez and J.-L. Deschanvres, Dalton Trans., 2018, 47, 2655-2661.

31 D. W. McOwen, S. A. Delp, E. Paillard, C. Herriot, S. D. Han, P. D. Boyle, R. D. Sommer, and W. A. Henderson, J. Phys. Chem. C, 2014, 118, 7781-7787

32 W. A. Henderson, J. Phys. Chem. B, 2006, 110, 13177-13183.

33 W. A. Henderson, Macromolecules, 2007, 40, 4963-4971.

34 T. Tamura, K. Yoshida, T. Hachida, M. Tsuchiya, M. Nakamura, Y. Kazue, N. Tachikawa, K. Dokko and M. Watanabe, Chem. Lett., 2010, 39, 753-755

35 K. Yoshida, M. Nakamura, Y. Kazue, N. Tachikawa, S. Tsuzuki, S. Seki, K. Dokko and M. Watanabe, J. Am. Chem. Soc., 2011, 133, 1312113129.

36 N. Tachikawa, K. Yamauchi, E. Takashima, J. W. Park, K. Dokko and M. Watanabe, Chem. Commun., 2011, 47, 8157-8159.

37 W. A. Henderson, N. R. Brooks, W. W. Brennessel, and V. G. Young Jr., Chem. Mater., 2003, 15, 4679-4684.

38 S. D. Han, S. H. Yun, O. Borodin, D. M. Seo, R. D. Sommer, V. G. Young Jr. and W. A. Henderson J. Phys. Chem. C, 2015, 119, 8492-8500.

39 W. A. Henderson, N. R. Brooks, and V. G. Young, Jr. Chem. Mater., 2003, 15, 4685-4690.

40 P. Johansson, S. P. Gejji, J. Tegenfeldt and J. Lindgren, Solid State lonics, 1996, 86-88, 297-302.

41 P. Johansson, J. Tegenfeldt and J. Lindgren, Polymer, 1999, 40, 43994406.

42 S. Mishra and S. Daniele, Chem. Rev., 2015, $115,8379-8448$.

43 E. S. Filatov, P. A. Stabnikov, P.P. Semyannikov, S. V. Trubin and I K. Igumenov, Russ. J. Coord. Chem., 2006, 32, 126-129.

44 E. S. Filatov, S. V. Sysoev, L. N. Zelenina, T. P. Chusova, V. A. Logvinenko, P. A. Stabnikov, P. P. Semyannikov and I K. Igumenov, J. Therm. Anal. Cal., 2006, 86, 537-539.

45 G. Malandrino, A. M. Borzì, F. Castelli, I. L. Fragalà, W. Dastrù, R. Gobetto, P. Rossi, and Paolo Dapporto, Dalton Trans. 2003, 369-374. 